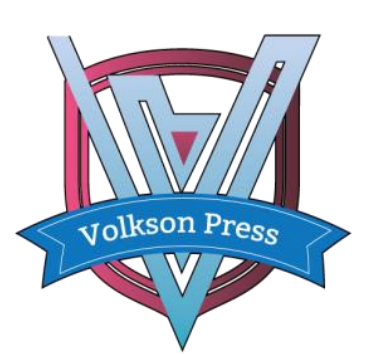

Contents List available at VOLKSON PRESS

Economics \& Management Innovations(EMI)

DOI : http://doi.org/10.26480/icemi.02.2018.10.12

ISBN: 978-1-948012-14-0

\title{
RESEARCH ON THE CODING METHOD OF SHIP BASED ON CENTRALIZED PURCHASING
}

\author{
Pan yanhua ${ }^{1,2}$, Xu ting ${ }^{*}$ \\ ${ }^{1}$ School of Economics and Management, Jiangsu University of Science and Technology, Zhenjiang 212003, China. \\ ${ }^{2}$ Jiangsu University of Science and Technology Service Manufacturing Model and Information Research Center. \\ *Corresponding Author Email: 1150124042@qq.com
}

This is an open access article distributed under the Creative Commons Attribution License, which permits unrestricted use, distribution, and reproduction in any medium, provided the original work is properly cited.

\section{ARTICLE DETAILS}

\section{Article History:}

Received 26 June 2018

Accepted 2 July 2018

Available online 1 August 2018

\section{ABSTRACT}

This paper analyzes the current status and problems of ship material coding from the perspective of centralized purchasing. Then, paper proposed a solution of material coding based on ontology in accordance with centralized purchasing. Finally, paper describes the generating process of ship material coding.

\section{KEYWORDS}

Ship material coding, centralized purchasing, ontology, automatic coding generator.

\section{INTRODUCTION}

With the great trend of the globalization of division of labor, the competition of shipbuilding has evolved from the competition between enterprises to the cooperative competition [1]. The synergistic essence of industrial chain is manifested in the integration and synergistic ability of resources [2]. Centralized purchasing as an important part of industrial chain management can effectively integrate the internal resources of enterprises [3]. It can summarize the different needs of many departments of the subsidiary and integrate it into a unified purchase order. It also can reduce the purchase cost and guarantee the quality of the purchase [4]. At present domestic shipyard mainstream material coding rule is to ship the material properties and form with the flexible code and fixed code combination of expression. The existing methods of the material code is non-uniqueness and material code does not reflect the problem such as material properties [5]. Based on centralized purchasing, this paper through the analysis of dispersion, analysis on the relationship between the ship goods between concepts, and on this basis to build the ship supplies domain ontology, determines the centralized purchasing mode of ship material classification and coding scheme.

\section{THE ONTOLOGY CONSTRUCTION FRAMEWORK OF MATERIAL CODING}

\subsection{Ontology and ontology construction techniques}

For the definition of ontology, the definition given by Studer in 1998 has a strong representativeness that ontology is the explicit formal specification of the Shared conceptual model [6,7]. This definition embodies the four layers of Ontology implication, namely, Capitalization, definition, formalization and sharing [8].

\subsection{The ontology process of material coding}

In this paper, the ship materials are studied in code, and the "7 steps" proposed by MeGuinness is chosen to construct the domain ontology. This paper will adopt a bottom-up method to construct the ship material domain ontology. On this basis, the classification and coding of ship materials are completed. Supplies the construction of ontology and classification and coding process: through the study of relevant information, shipping supplies including shipping industry in the production and construction, design, procurement, sales, research and other supplies, involved in the definition of materials, properties, the concept of; Then, according to the nature of ship materials, the class system of ship materials is completed. Secondly, the properties of class are defined by multifaceted method. Finally, the code of uniform norms for all kinds of materials and their relations is carried out.

\section{A MATERIAL CODING METHOD AND AN EXAMPLE BASED ON ONTOLOGY THEORY}

\subsection{Construct the framework of ship material coding ontology}

According to the ship material and its ontological properties, classification of ship materials is carried out using line classification. In classification, starting from the basic concept of shipping supplies, ship supplies the basic concept of information contained, and the relationship between the basic concept and the concept. Build ship supplies the basic framework of ontology is shown in figure 1 .

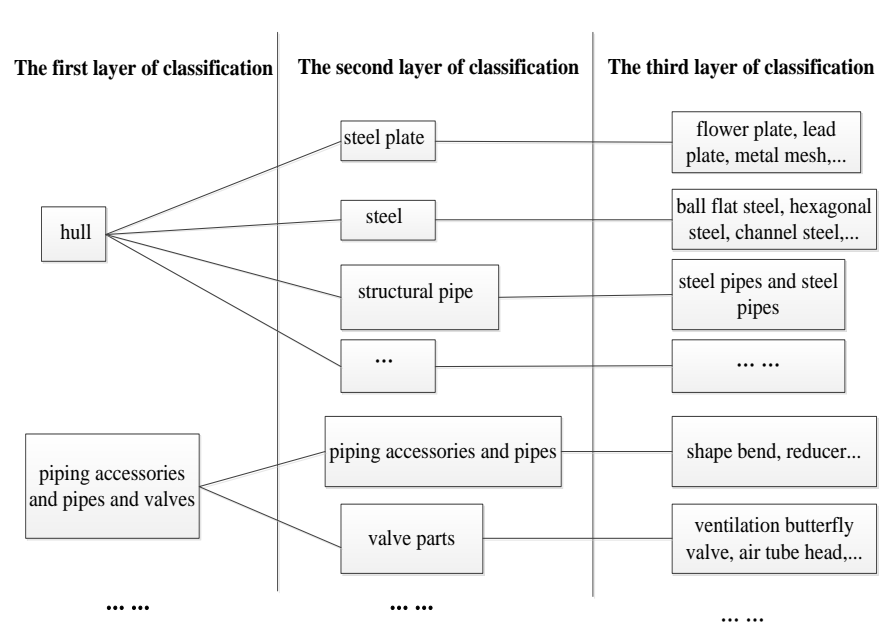

Figure 1: Frame diagram of the ship's material ontology 


\subsection{Establishment of the classification system of ship materials}

According to the figure 2 which shows the ship material ontology framework and the framework of ontology contains various categories of ship goods, sort out the basic relationship between the material fields of ships and express the core concept of domain ontology as an accurate term or chart. From the perspective of conceptual semantics, there are three basic relationships of ship materials:

1. Kind-of: Inheritance of concepts. Figure 2 describes the relationship between the shape steel and the flat steel and the hexagon steel:

2. Attribute-of: A concept is an Attribute of another concept. For example, the material, thickness, width and length are all attributes of steel plate. For ordinary steel tube, material, diameter, thickness and length are the properties of steel pipe. The following figures are shown in figure 3 and figure 4 :

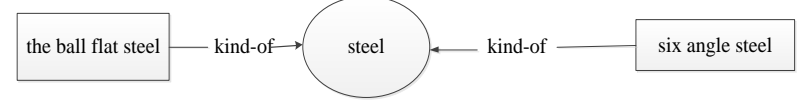

Figure 2: The diagram of the relationship between the shape steel and the flat steel and the hexagonal steel.

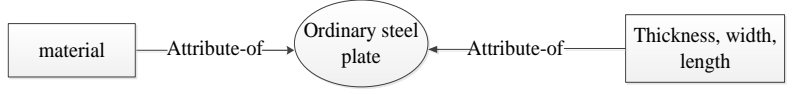

Figure 3: Conceptual diagram of normal steel plate with material, thickness, width and length

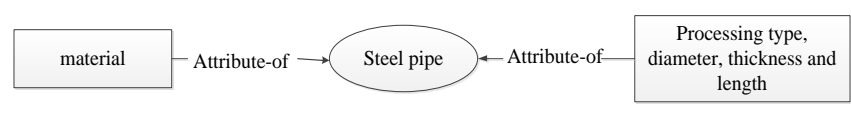

Figure 4: Conceptual diagram of normal pipe and material, diameter, thickness and length

Collate and divide all the key concepts and their relationships accordingly. The important concepts of the device information example and the relationship between them are sorted and hierarchical, and a complete hierarchical conceptual diagram is obtained, as shown in figure 5.

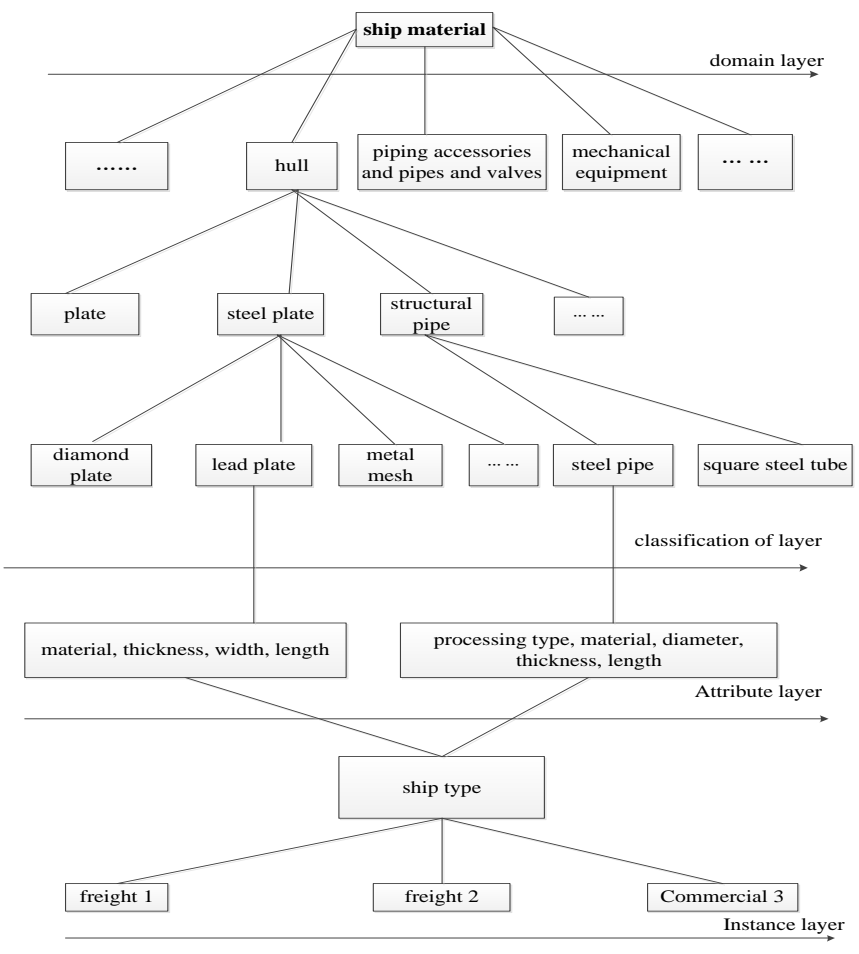

Figure 5: Example of ship material ontology construction

\subsection{Defines the properties of the class}

The "class" describes the framework of the ship's materials field, which can accurately describe the field of ship materials by determining the attributes of the class and defining the internal structure of the class. As shown in figure 4 plain steel, its properties are: material, thickness, width and length.

\subsection{Uniform coding of material classification of ships}

The classification encoding adopts pure numeric coding, the length of the classification codes at all levels is fixed, and the minimum value of the capacity demand and expansion is met. The material coding in the classification of the same layer is adopted in the form of uniform watermark.

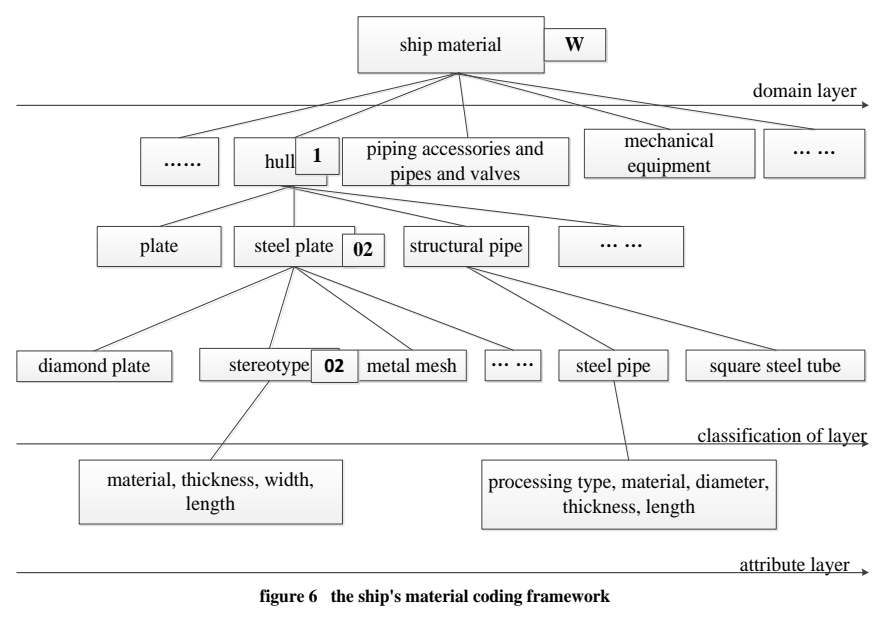

Figure 6: The Ship's material coding Framework.

The coding of the domain layer and classification layer is shown in the figure 6 above. The categories involved in the ship are coded by $1,2 \ldots . .$. The section of the hull classification, steel plate, etc., with two numerical codes. Steel plate, lead plate and so on also use two numerical codes. For the coding of the attribute layer, because there are many kinds of materials in the shipping industry, the coding is complex, we refer to the ship material attribute element coding comparison table.

Common steel plate, for example in figure 4, bom's record is: lead plate A $6 * 1500 * 1500 \mathrm{CCS}$, the corresponding standard description template for goods name material thickness length * width * classification, according to standard delimiter is confirmed in the description of goods (such as space) will receive the material list of material description information is split into several materials description elements, such as lead plate $6 * 1500 *$ 1500 CCS into A lead plate; A;6;1500;8000;CCS, corresponding to its material description standard template of the material name; Material; Thickness; The width; Length; The classification society. Find the corresponding encoding in the element library by parsing the material element.

The following table 1 is the material attribute element encoding table:

Table 1: The material attribute element encoding table

\begin{tabular}{|l|l|l|l|}
\hline $\begin{array}{l}\text { element } \\
\text { number }\end{array}$ & element name & encoding & element value \\
\hline 00001 & classification society & C & CCS \\
\hline 01002 & length & 08 & 8000 \\
\hline 01003 & breadth & $1 \mathrm{~B}$ & 1500 \\
\hline 01004 & thickness & 05 & 5 \\
\hline 01004 & material & A0 & A \\
\hline$\ldots$ & $\ldots$ & $\ldots$ & $\ldots$ \\
\hline
\end{tabular}

Link the element values which be found from the corresponding coding according to the order of the elements of the original, according to the principle of the code generator, lead plate of A $6 * 1500 * 1500$ CCS 
material attribute coding as material, thickness, width, length, classification society (in this paper, the default classification for CCS) coding for: W10202A0061B08C.

\section{CONCLUSIONS}

Under the environment of centralized procurement, ship material management is a major problem of shipbuilding industry. This article through to ship material ontology framework, and has carried on the elaboration of the ontology architecture design, set up a Shared ontology of ship supplies can be updated in real time, coded to ship material, has realized the effective integration of ship goods coding, convenient for the same enterprise between different departments and different ship company ship supplies the sharing of information, to ship the centralized purchasing to create a better conditions of the enterprise.

\section{FUND OF THE PROJECT}

1.Major projects of the key research base of philosophy and social science in colleges and universities of jiangsu province (2015JDXM023): Research on shipping industry chain manufacturing service model. 2.The development and reform commission's special fund project for the development of strategic emerging industries of jiangsu province ( 71303096): Ship and ocean engineering industry chain digital manufacturing service platform.

\section{REFERENCES}

[1] Hu, C., Jing, Z. 2013. A cross-industry information service coordination organization for industrial chain [J]. Intelligence magazine.

[2] Zhang, Z., Zheng, S.X. 2013. The relationship between the technical ability and the integration of industrial chain - with blond technology as an example [J]. China science and technology BBS.

[3] Song, Y. 2014. Research on centralized purchasing strategy based on supply chain optimization - A case study of non-productive material procurement in A company [D]. Shanghai: Shanghai foreign studies university.

[4] Wang, H., Zhang, G., Xie, P. 2006. The advantages of shipbuilding industry cluster based on shipbuilding supply chain [J]. Ship materials and market.

[5] Pan, Y., Mou, C. 2012. Research on ship material coding based on the design and production of production [J]. Ship science and technology.

[6] Luo, J. 2015. research and application of centralized purchasing management based on information [J]. finance and economics.

[7] Hungarian guo , research and application of semantic web based on ontology [D], xi 'an: xi 'an electronic technology anthropology, 2005.

[9] Nechesr, Fkesre, Grubertr. 1991. Enabling technology for knowledge sharing[J]. AIM agazine, 12 (3), 36-56. 